\title{
Evaluation of Ejector Performance for an Organic Rankine Cycle Combined Power and Cooling System
}

\author{
Kun Zhang ${ }^{1,2}$, Xue Chen ${ }^{3}$, Christos N. Markides ${ }^{2}$, Yong Yang ${ }^{3}$, Shengqiang Shen ${ }^{3}$ \\ ${ }^{1}$ School of Ocean and Civil Engineering, Dalian Ocean University, Dalian, China, 116023 \\ ${ }^{2}$ Clean Energy Processes (CEP) Laboratory, Department of Chemical Engineering, Imperial College London, \\ London SW7 2AZ, United Kingdom \\ ${ }^{3}$ School of Energy and Power Engineering, Dalian University of Technology, Dalian, China, 116024
}

\begin{abstract}
Power-generation systems based on organic Rankine cycles (ORCs) are well suited and increasingly employed in the conversion of thermal energy from low temperature heat sources to power. These systems can be driven by waste heat, for example from various industrial processes, as well as solar or geothermal energy. A useful extension of such systems involves a combined ORC and ejector-refrigeration cycle (EORC) that is capable, at low cost and complexity, of producing useful power while having a simultaneous capacity for cooling that is highly desirable in many applications. A significant thermodynamic loss in such a combined energy system takes place in the ejector due to unavoidable losses caused by irreversible mixing in this component. This paper focuses on the flow and transport processes in an ejector, in order to understand and quantify the underlying reasons for these losses, as well as their sensitivity to important design parameters and operational variables. Specifically, the study considers, beyond variations to the geometric design of the ejector, also the role of changing the external conditions across this component and how these affect its performance; this is not only important in helping develop ejector designs in the first instance, but also in evaluating how the performance may shift (in fact, deteriorate) quantitatively when the device (and wider energy system within which it functions) are operated at part load, away from their design/operating points. An appreciation of the loss mechanisms and how these vary can be harnessed to propose new and improved designs leading to more efficient EROC systems, which would greatly enhance this technology's economic and environmental potential. It is found that some operating conditions, such as a high pressure of the secondary and discharge fluid, lead to higher energy losses inside the ejector and limit the performance of the entire system. Based on the ejector model, an optimal design featuring a smoothed nozzle edge and an improved nozzle position is found to achieve an improved entrainment ratio, significantly better performance and reduced energy losses in the ejector.
\end{abstract}

Keywords: Ejector; Refrigeration; Combined Cooling, Heating and Power

\section{Nomenclature}
Abbreviations
COP Coefficient of performance
EORC Organic Rankine cycle plus ejector
ER Entrainment ratio

\footnotetext{
${ }^{1}$ Corresponding author: Kun Zhang. Tel: +86 15542663303. Email: cruiseer@hotmail.com
} 


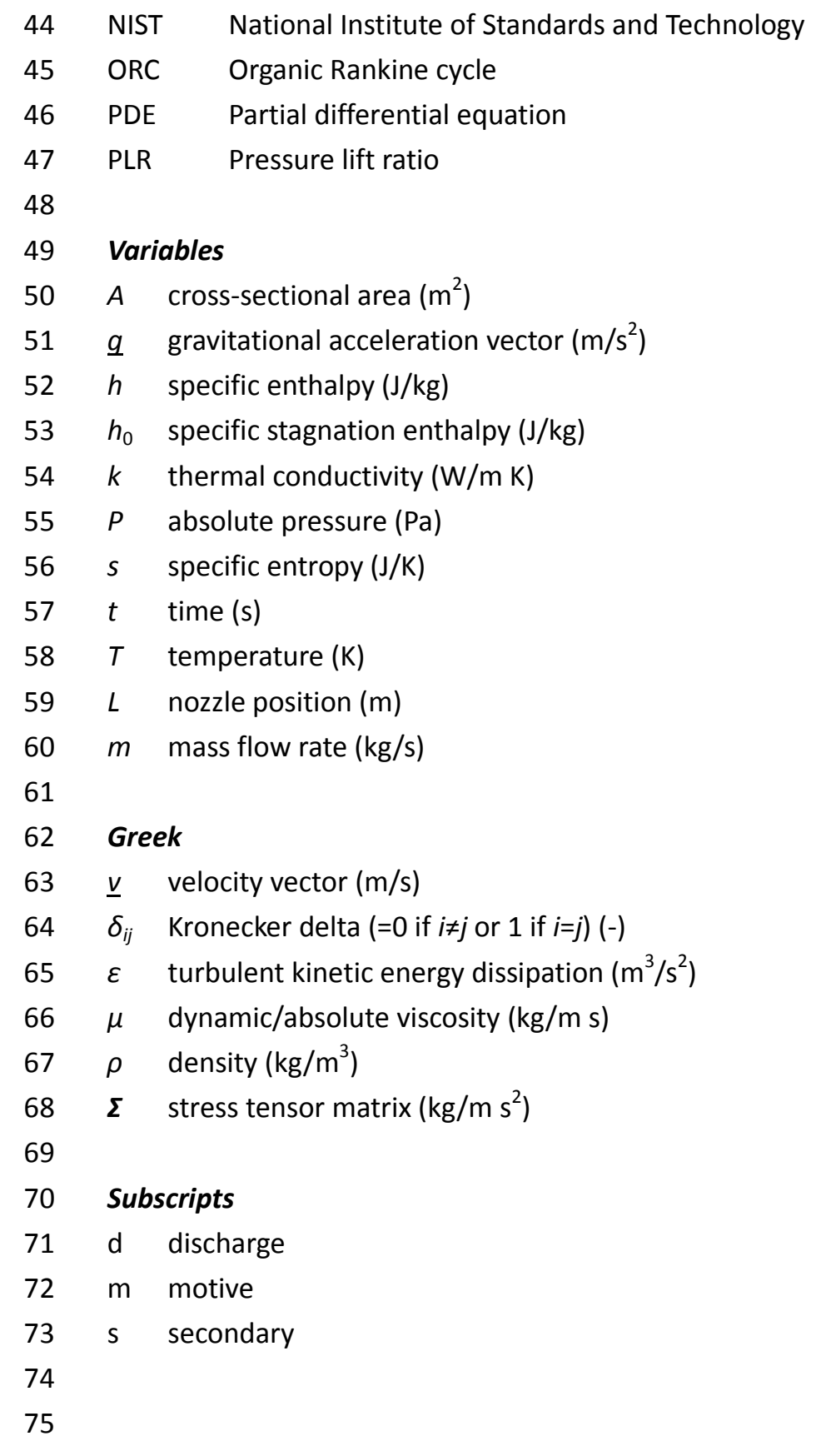

\section{Introduction}

77

Energy is essential to sustaining life, and to promoting economic and social development and well-being. Its careful use is increasingly recognized as a critical aspect of many industrial and environmental processes. Recovering and utilizing low- and medium-grade heat (typically thought of as heat at temperatures in the range $60^{\circ} \mathrm{C}$ to $300^{\circ} \mathrm{C}$ ), including waste heat from industrial processes but also geothermal heat and solar energy when using non-concentrated or low-concentration collectors, amongst other, is a compelling, significant and promising way to address existing global energy-related challenges in a sustainable manner [1,2]. In particular, organic Rankine cycle (ORC) systems are highly suitable for generating power from these low- to medium-grade/temperature thermal-energy sources at scales which are most appropriate to distributed power generation up to an order of about $10 \mathrm{MW}$, and their use has been increasing 
exponentially in recent years [2-6]. High reliability and flexibility also contribute at making the value proposition of ORCs attractive [7-11]. Currently, more than 600 such units are installed worldwide with a cumulative capacity in excess of $2000 \mathrm{MW}$.

Unfortunately, the current economic proposition offered by ORC systems in many applications is still acting to limit their even greater use in the industrial, but also commercial and domestic sectors. In addition, it is often and increasingly the case that cooling is required due to advancements and an increasing penetration of thermal insulation in many building applications. Moreover, in solar applications it is often the case that systems are required in geographical locations with hot ambient conditions and good solar resource that favours the provision of cooling. In order to improve the overall efficiency of relevant systems, while supplying a simultaneous cooling capacity, a variety of combined power and cooling systems have been proposed. Relevant systems can be classified as belonging to two categories, depending on whether they are based on: (i) absorption combined cycles [12]; or (ii) ejector combined cycles [13-15]. In either case, these systems aim to improve the overall efficiency of primary-energy utilisation compared to conventional standalone power-generation systems.

The former (i.e. absorption combined cycles) are relatively established and have been in use for some time but are relatively costly, whereas the latter are simpler and have attracted increasing attention in the recent literature. One example of the former was proposed in the mid-1990s by Goswami [16]. This combined power and cooling system, shown in Figure 1, was aimed for use with low-grade heat sources $\left(<200^{\circ} \mathrm{C}\right)$ and combined a Rankine heat-engine cycle for power generation and an ammonia-water absorption-refrigeration cycle.

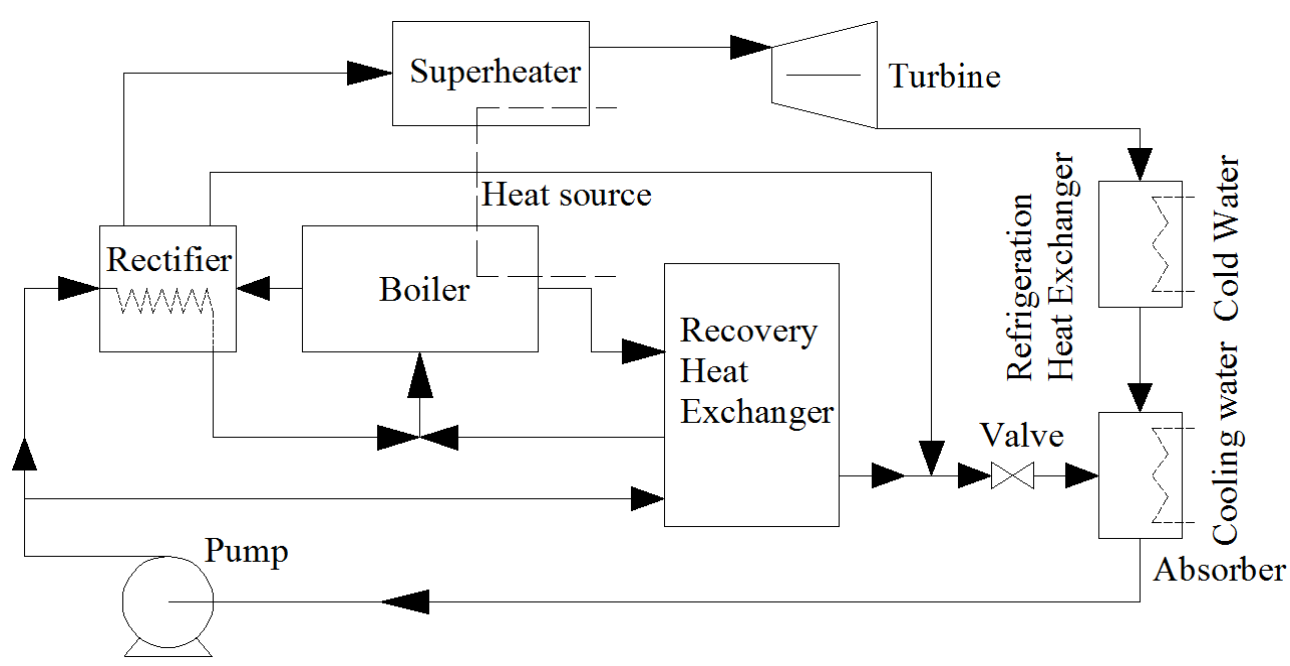

Figure 1: Schematic of combined ORC and ammonia-water absorption-refrigeration system

A number of studies [17-19] have analysed the combined system proposed by Goswami [16], both theoretically and experimentally. From these efforts, it has been concluded that the system is indeed capable of utilizing low-grade heat effectively; however, the cooling capability of the system is relatively low while its complexity is high. This has led other investigators to suggest alternative combined power and cooling configurations, based on the employment of an ejector (single component) as opposed to a refrigeration sub-system, the aim always being to recover low-grade heat effectively while utilizing the advantages of the ejector-refrigeration cycle. 
The ejector was invented and found application in the early 1900s in the context of steam engines [20], but it was not until the energy crisis in the 1970s that it received renewed interest, either as a mechanical-compressor replacement or simply for cycle optimization in an attempt to develop energy efficient technologies; these efforts are now augmented by a keen interest in environmental responsibility. Nowadays, the ejector is an essential component of numerous systems with diverse applications in refrigeration, air conditioning/HVAC, oil refining, desalination, and many other uses in the chemical, petrochemical industries and manufacturing [21].

An early theory for perfect gases flows through ejectors was developed by Keenan [22,23], following which a number of theoretical, computational and experimental studies were performed aimed at understanding the fundamental underlying fluid flow and heat transfer processes that take place in these components and how these affect operational behaviour and performance [24-27]. More recent studies [28-30] have accounted for real-fluid effects, since ejectors typically operate close to the two-phase region.

Figures 2, 3 and 4 illustrate 3 types of systems featuring an ORC with an ejector (EORC), the differences of which are where primary fluid-flow comes from. Oliveira et al. [31] proposed a combined ejector and Rankine system, in Figure 2, which supply electricity and cooling capacity at the same time with only one heat source. The power from generator was divided into two parts to drive turbine and ejector separately. When the heat source is at $95{ }^{\circ} \mathrm{C}$, the refrigeration system achieves a coefficient of performance (COP) of 0.3 and a power generation efficiency of 3 $-4 \%$. However, it is difficult to balance pressure from the exit of turbine and ejector.

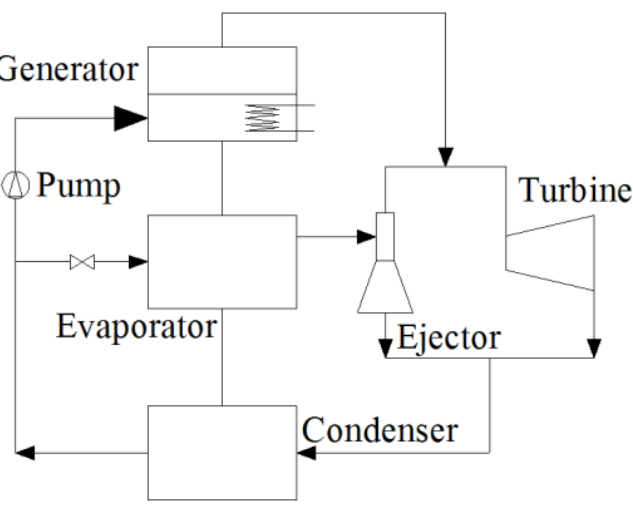

Figure 2: Schematic of EORC combined system with ejector primary flow from generator [31]

Figure 3 is a schematic of a system proposed by Li et al. [32] and Yari et al. [33]. In this organic Rankine cycle arrangement featuring an ejector (EORC), the primary fluid (vapour) flow for the ejector is taken from the second-stage evaporator and the ORC expander outlet is connected to the secondary-flow inlet port of the ejector. A beneficial consequence of this EORC arrangement is that it leads to an enhancement in the pressure ratio across the expander, and consequently, an increase of the power output of the expander (and, therefore, of the whole system). On the other hand, the cooling capacity attained by the system is relatively small. 


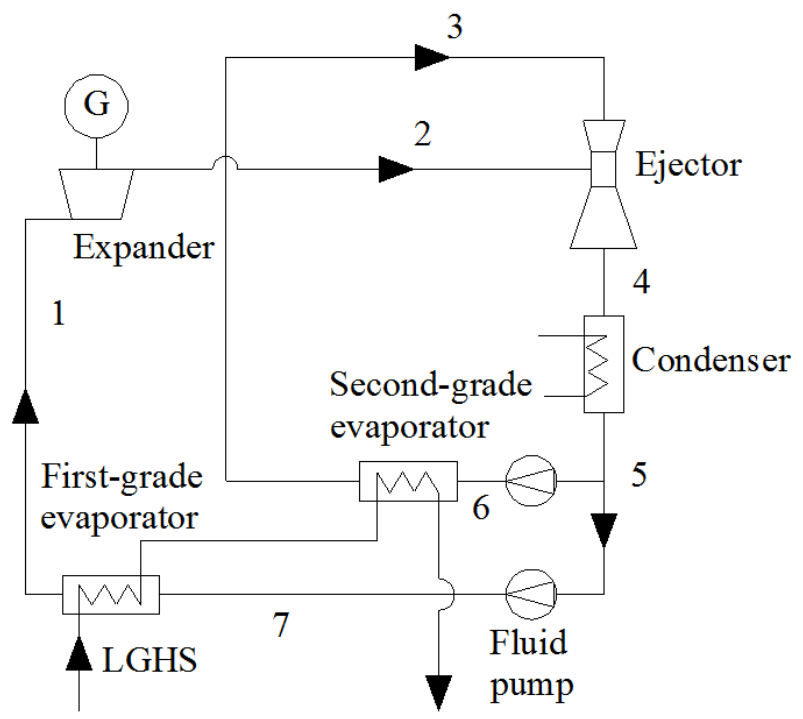

Figure 3: Schematic of EORC combined system with ejector primary flow from evaporator $[32,33]$

A promising alternative EORC system configuration, shown in Figure 4, was suggested by Dai et al. [34] with R123 as the working fluid. In this system, an ORC power cycle is combined with an ejector-refrigeration cycle, with the primary flow for the ejector taken from the exit of the ORC sub-system turbine and the secondary flow taken from the ejector sub-system evaporator, which is positioned downstream of the throttling valve of the ejector-refrigeration sub-system. In their paper, Dai et al. [34] reported that the: (i) turbine inlet and outlet pressures, and (ii) condenser and evaporator temperatures, have significant effects on the turbine power output, but also on the cooling capacity of the combined system, with the heat addition components and, less so, the ejector being associated with most of the losses in performance.

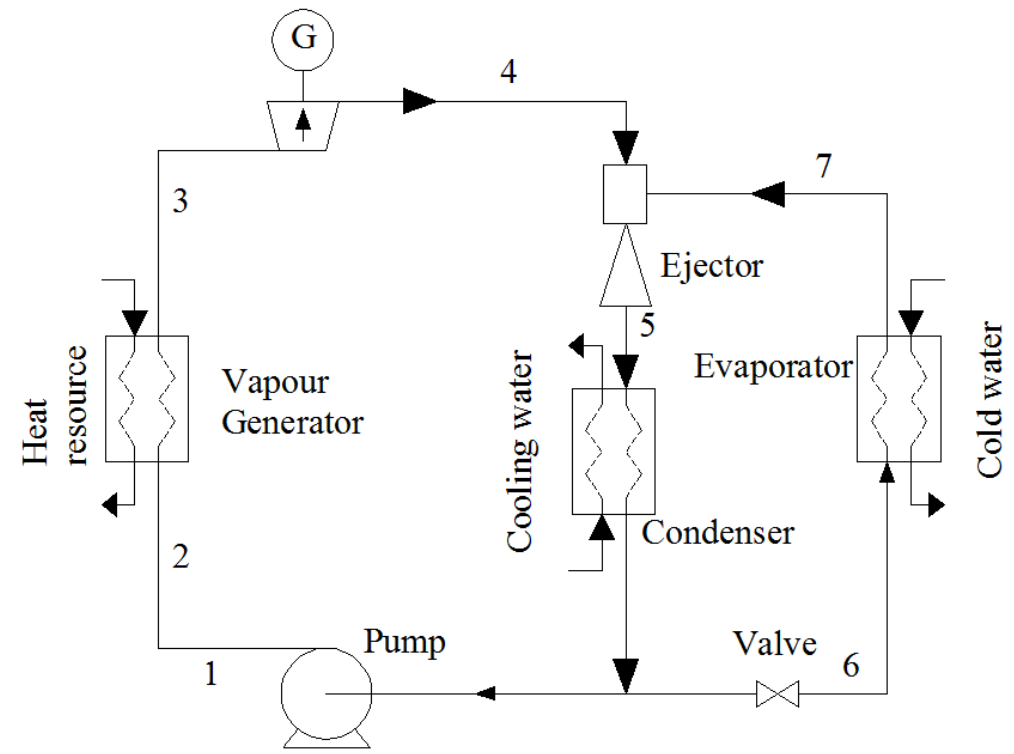

Figure 4: Schematic of EORC combined system with ejector primary flow from turbine [34-36]

The performance of the same EORC system was investigated by Zheng and Weng [35] who 
analysis performed in this study showed that this cycle is capable of delivering a significant cooling capacity, and again, identified the ejector as an important component in terms of its contribution to the overall losses in the entire system.

In a related study of interest, Wang et al. [36] considered the performance of a modified version of the above system, also with refrigerant R123 and the same external-temperature conditions. In this system, a fraction of the flow through the turbine was bled without being allowed to expand fully and supplied to the ejector as the primary fluid, as opposed to the fully expanded fluid at the exit of the turbine. In this case, the (remaining) fluid stream at the turbine exit is mixed irreversibly with that at the ejector exit. Similar results were obtained to the study of Dai et al. [34]. Furthermore, considerations of the exergy efficiency of individual system components indicated that the largest loss is associated with, in decreasing magnitude: (i) the vapour generator; (ii) the ejector; and (iii) the turbine. This finding is particularly interesting, and important, as it confirms the role of the ejector as a crucially important component whose losses must be considered with particular care if high overall system efficiency is to be achieved.

In summary, there is little doubt that the incorporation of an ejector into an ORC system gives rise to an interesting and versatile power and cooling technology, which has the potential to play an important role in addressing the global energy challenge. The present article considers the energy losses of a whole EORC (ORC plus ejector) system, which usually consist of three parts: nozzle losses, friction in the mixing chamber and shock-wave formation [37]. The aim here is to focus on analysing the flow field inside the ejector with a view towards optimizing the ejector design by reducing energy (and also exergy) losses, and thus improving the efficiency of the EORC system, leading a much-improved economic and environmental proposition.

\section{Cycle Description}

The EORC system shown in Figure 4 is selected as the basic cycle for consideration in this work. The main advantage of this particular system lies in its ability to provide a varying cooling capacity thanks to the adjustable exit pressure at the outlet of the turbine, which makes it a flexible device for the combined production and provision of power and refrigeration. The thermodynamic cycle diagram of the EORC system in Figure 4 is shown in Figure 5.

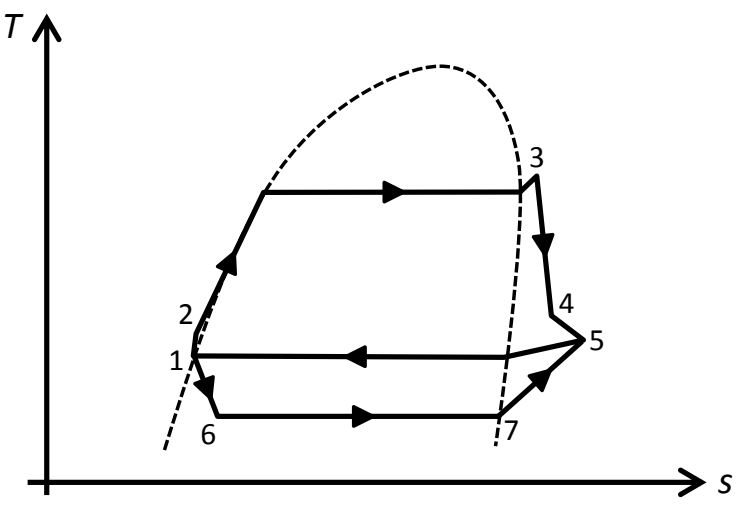


In more detail, we consider the cycle starting from State 1 in Figure 5, where the working fluid is a saturated liquid. From this state, the working fluid is pumped to the entrance of the vapour generator (high-temperature/pressure evaporator of the ORC power-cycle) at State 2 as a slightly subcooled liquid. As it flows through the vapour generator while taking heat from the low-grade heat source at constant pressure (isobarically), the liquid is first preheated to the wet saturation (liquid) curve (bubble point), evaporated isothermally to the dry saturation (vapour) curve (dew point), and then slightly superheated to State 3. After exiting the evaporator at State 3, the superheated vapour is expanded in a turbine in order to generate useful mechanical work, which can later be converted to electricity with the use of a generator.

Referring also to Figure 4, the vapour then exits the turbine as a superheated vapour at State 4, from which point it flows into the ejector as the primary (or, motive) fluid stream. As it flows through the nozzle of the ejector, the primary fluid undergoes an additional expansion process to a lower pressure, after which it mixes with the vapour stream exiting the low-temperature/pressure evaporator of the ejector cooling-cycle at State 7 that is entrained into the ejector as the secondary fluid stream, as mentioned earlier. It is assumed that the primary and secondary fluid streams mix in the ejector at constant pressure. Following this mixing process, the vapour undergoes pressure recovery to State 5, from which it enters the only condenser in the system. In this component, the superheated vapour is first desuperheated isobarically from State 5 to the dew point, and the condensed isothermally (and isobarically, since this process occurs inside the saturation region) to the bubble point by an external cooling water stream (sink). Following condensation, the working fluid exits the condenser as a saturated liquid at State 1 , and is then split into two streams. One of these streams returns to the ORC sub-system pump in order to take part in the ORC power-cycle, while the other flows into the ejector sub-system in order to take part in the ejector-cooling cycle. The latter involves, first, an isenthalpic flow process through an expansion valve to State 6, followed by an isobaric flow process through the low-temperature/pressure evaporator. The cooling effect from this combined cycle is produced when the cold water at the lowest temperature in the cycle rejects heat to the working fluid stream during the evaporative process from State 6 to State 7.

\section{Model Development and Validation}

\subsection{Ejector background}

The ejector is a type of pump, whose operating principle is based on the Venturi effect as this applies to flows through converging-diverging nozzles. Referring to Figure 6, firstly, a primary nozzle injects a high-velocity primary/motive fluid stream into a converging section known as the mixing chamber, while entraining a secondary, low-pressure suction fluid into the chamber. The fluid used in the primary/motive stream may be a liquid, gas or vapour (e.g. steam). At the exit of the primary nozzle in the mixing chamber a low-pressure region is established that draws in the secondary flow of the suction fluid, leading to mixing of the two fluid streams inside the ejector chamber. This arrangement effectively converts the mechanical energy (pressure) in the initially high-pressure primary flow of the motive fluid to kinetic energy (velocity) as the flow cross-sectional area decreases and the fluid accelerates though the nozzle and into the mixing chamber. According to Refs. [37,38], this mixing process can be assumed to occur at constant 
pressure, as stated earlier. This first process inside the ejector, which involves the expansion of a higher-pressure (primary) flow downstream of the nozzle, entrainment and mixing with a lower-pressure (secondary) flow in the mixing chamber, is followed by flow of the mixed fluid into a diffusing section via a throat, after which the mixed fluid exits from the outlet of the ejector. The increasing cross-sectional flow area of the diffuser acts to reduce the velocity of the mixed-fluid flow, as kinetic energy is recovered and converted back into an increase in pressure.

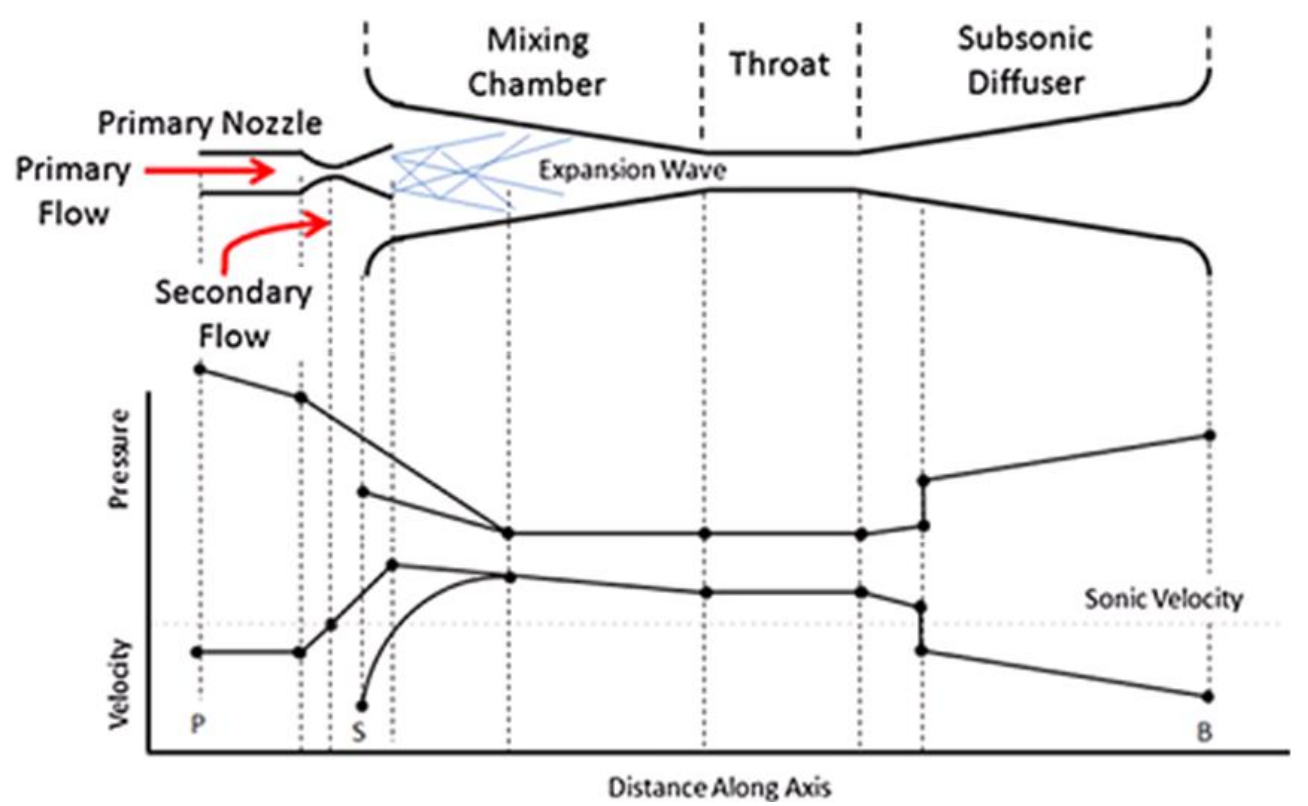

Figure 6: Schematic of ejector sections, with pressure and velocity profiles in the flow direction

When the pressure at the exit of the primary nozzle is below a certain critical value, which only depends on the properties of the fluid and on the supplying backpressure of the primary stream from the exit of the turbine (assuming isentropic flow through the primary nozzle), the primary stream is accelerated through this nozzle and delivered to the mixing chamber at supersonic speeds. This is the case illustrated in Figure 6. The secondary stream is then entrained by accelerating quickly into the mixing chamber due to the lower pressure in this region compared to the pressure in the evaporator where this stream originates.

Depending on the geometry of the ejector design, the flow may or may not continue through the ejector in a supersonic state, since the converging mixing-chamber section and the constant-area throat will both act to decelerate the flow as the static pressure rises, as predicted by one-dimensional compressible-flow theory for supersonic isentropic flows through converging sections and for supersonic flows through constant-area ducts with friction. Furthermore, the mixed flow can be decelerated by a series of shocks (either normal and/or oblique waves) in the mixing chamber [39]. On the other hand, the flow may remain supersonic through the mixing chamber, as well as through the constant-area throat section if the so-called 'shock-train' is not strong enough [40] as shown in Figure 6. Either way, even if the flow remains supersonic, it will accelerate in the diffusing section until a shock eventually causes a sharp rise in pressure and drop in speed to subsonic conditions. Downstream of this point, the flow is subsonic, yet still compressible, with friction and of the increasing flow area acting to continuously decelerate flow as the pressure recovers (increases) until the exit of the ejector into the condenser (discharge). 
It is possible to classify ejectors as belonging to one of two main designs depending on the position within the ejector of the primary nozzle [41]. With reference to Figure 6 , if the exit plane of the nozzle is located within the suction chamber (convergent section) of the ejector and in front of the constant-area throat section, the mixing process can be assumed to take placed under constant (static) pressure conditions and the ejector is commonly referred to as a constant-pressure mixing ejector; this is the arrangement explored in the present paper, whose analysis, consequently, requires the employment of constant-pressure theory. If, however, the nozzle is positioned such that its exit plane is located within the constant-area section, the ejector is referred to instead as a constant-area mixing ejector. It has been found that the constant pressure ejector shows better performance compared to the constant area variant [39].

Two commonly used parameters will be used herein to characterize ejector performance, namely the 'entrainment ratio' [42] and the 'pressure lift ratio', which are defined as:

$$
\text { Entrainment ratio: } \mathrm{ER}=\frac{\dot{m}_{2}}{\dot{m}_{1}}
$$

$$
\text { Pressure lift ratio: } \mathrm{PLR}=\frac{P_{\mathrm{d}}}{P_{2}}
$$

where $\dot{m}_{1}$ and $\dot{m}_{2}$ are the inlet mass flowrates of the primary and secondary streams, respectively, and $P_{2}$ and $P_{\mathrm{d}}$ are the static pressures at the inlet (supply) of the secondary stream and at the exit of the entire ejector; the latter is also known as the discharge pressure.

The first parameter, i.e. the entrainment ratio (ER), is considered a key indicator because it affects the performance (COP) of the entire cooling system, while the second parameter, i.e. the pressure ratio (PLR), affects the system's heat-rejection temperature [43]. Based on these two performance indicators, an ejector is desired with the highest possible entrainment and that maintains the highest possible discharged pressure, when operating at given conditions.

In all cases, as with the previously mentioned system configurations, the mass flow rate exiting the ejector is the combined sum of the mass flow rates of the primary and secondary fluid streams entering the converging-diverging nozzle of the ejector, by conservation of mass.

\subsection{Basic 'nominal' ejector geometric design}

The investigated nominal ejector was designed as per Ref. [44] by using a 1-D model based on constant-pressure theory $[37,41]$, as mentioned earlier. A dimensional technical drawing of the resulting design is shown in Figure 7, with detailed characteristic dimensions given in Table 1 . The design was based on an operating point with the following characteristics: a motive pressure of $P_{1}=780 \mathrm{kPa}$, a secondary pressure of $P_{2}=229 \mathrm{kPa}$, and a discharge pressure of $P_{\mathrm{d}}=308 \mathrm{kPa}$.

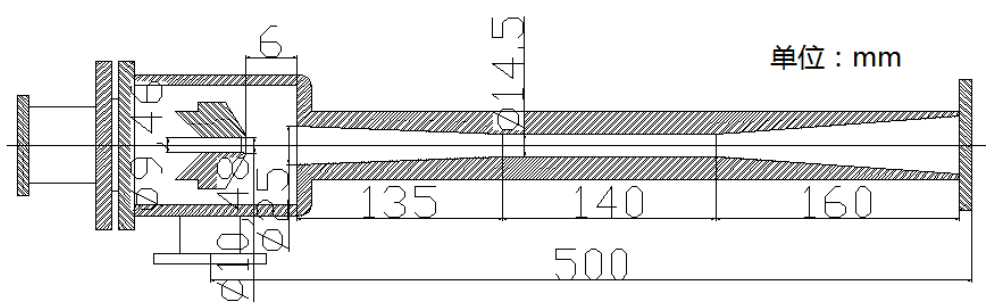

Figure 7: Technical drawing of the nominal ejector geometry considered, with full dimensions 
Table 1: Key geometry parameters of the nominal ejector design based on the 1-D model [44]

\begin{tabular}{|c|c|}
\hline Key parameters of ejector & Size $(\mathbf{m m})$ \\
\hline Nozzle entrance diameter & 35.0 \\
\hline Nozzle throat diameter & 9.5 \\
\hline Nozzle exit diameter & 10.5 \\
\hline Constant-area diameter & 14.5 \\
\hline Nozzle exit to mixing chamber & 6.0 \\
\hline Mixing chamber length & 135.0 \\
\hline Diffuser length & 160.0 \\
\hline
\end{tabular}

316

\subsection{CFD model, meshing and boundary conditions}

A series of two-dimensional (2-D) CFD simulations were performed to predict the flow (and pressure) through various ejector designs, and to perform parametric studies around the nominal ejector design (given in Table 1) based on the effects of geometrical changes (specifically, the position of the nozzle exit) and of changes to the conditions across the component, leading to an evaluation of the losses of interest. The flow field in an ejector is in most engineering applications compressible and turbulent, and the fluid is assumed to be Newtonian and isotropic. In this case, the full governing equations that must be solved for the pressure $(P)$, velocity vector $(v)$ and temperature $(T)$ fields throughout the ejector arise from equations for the conservation of mass (continuity), momentum and energy in the flow, and are given below:

$$
\frac{\mathrm{D} \rho}{\mathrm{D} t}+\rho \nabla \cdot \underline{v}=0
$$

$$
\rho \frac{\mathrm{D} \underline{\underline{v}}}{\mathrm{D} t}=-\nabla P+\nabla \cdot \Sigma+\rho \underline{g}
$$

$$
\rho \frac{\mathrm{D} h_{0}}{\mathrm{D} t}=\frac{\mathrm{D} P}{\mathrm{D} t}-\underline{v} \cdot \nabla P+\nabla \cdot(k \nabla T)+\nabla \cdot(\boldsymbol{\Sigma} \cdot \underline{v})+\rho \underline{g} \cdot \underline{v}+\rho \dot{q}
$$

It is assumed that the processes occurring in the ejector considered in the present work (indicated in Figure 6) are steady, axi-symmetric and adiabatic, and that the work done by/on the fluid, internal dissipation or any effects of gravity are negligible. The velocities at the inlet (motive/primary and secondary) and outlet (discharge) of the ejector are considered small compared to elsewhere in the device. Based on these assumptions on the flow through the ejector, a series of simplifications can be made to the above equations before these are solved, such that it can be further assumed that the flow is two-dimensional [45] $(i=j=1,2)$ and obeys:

$$
\begin{aligned}
& v_{j} \frac{\mathrm{d} \rho}{\mathrm{d} x_{j}}+\rho \frac{\mathrm{d} v_{j}}{\mathrm{~d} x_{j}}=\frac{\mathrm{d}\left(\rho v_{j}\right)}{\mathrm{d} x_{j}}=0 \\
& \rho v_{j} \frac{\mathrm{d} v_{i}}{\mathrm{~d} x_{j}}=-\frac{\mathrm{d} P}{\mathrm{~d} x_{i}}+\frac{\mathrm{d}}{\mathrm{d} x_{j}}\left[2 \mu \varepsilon_{i j}-\frac{2}{3} \mu\left(\frac{\mathrm{d} v_{k}}{\mathrm{~d} x_{k}}\right) \delta_{i j}\right] ; \varepsilon_{i j}=\frac{1}{2}\left(\frac{\mathrm{d} v_{i}}{\mathrm{~d} x_{j}}+\frac{\mathrm{d} v_{j}}{\mathrm{~d} x_{i}}\right) \\
& \rho v_{j} \frac{\mathrm{d} h_{0}}{\mathrm{~d} x_{j}}=\frac{\mathrm{d}}{\mathrm{d} x_{j}}\left(k \frac{\mathrm{d} T}{\mathrm{~d} x_{j}}\right)+\frac{\mathrm{d} \Sigma_{i j} v_{j}}{\mathrm{~d} x_{j}}
\end{aligned}
$$

The simultaneous solution of Equations (6) - (8) requires (and depends on) the specification of suitable boundary conditions. Constant (and uniform) pressure levels can be imposed at the ejector's two inlets and at its (single) outlet, thereby matching the saturation conditions in the evaporator and condenser of the overall combined cycle (see Figures 4 and 5), while the temperature of the generator is usually set to be slightly superheated, as it has been found to be beneficial to ejector performance [41]. Moreover, since the processes through the ejector are assumed to be globally adiabatic, all walls are considered to be adiabatic boundaries for the 
energy (temperature) equation and a no slip boundary condition for the velocity.

In this investigation, ANSYS has been employed to solve the above stated equations in 2-D assuming axi-symmetric flow (which is a frequently used assumption in ejector flows $[40,46]$ ), by employing a $k-\varepsilon$ RNG turbulence model that was found to predict accurately the entrainment processes in jet flows $[47,48]$. The final form of the transport equations for the turbulent kinetic energy $(k)$ and energy dissipation rate $(\varepsilon)$ can be found in the ANSYS User Guide.

The CFD flow geometry was a structured mesh generated by using the Gambit meshing tool. A number of mesh densities were examined in order to assess grid independence, with the final mesh consisting of 200,578 quadrilateral cells. The mesh for the ejector design shown in Figure $8 \mathrm{a}$ and the refined mesh around the ejector's nozzle exit are illustrated in Figure $8 \mathrm{~b}$. In all simulations presented in this paper a turbulence intensity of $5 \%$ was imposed at the inlet of all flows, based on the approximate value expected in a fully developed pipe flow.

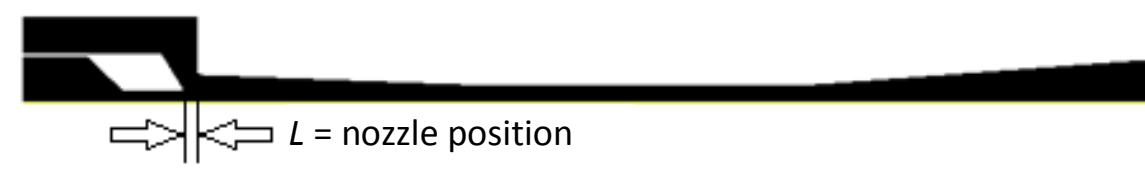

(a)

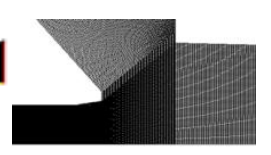

(b)

Figure 8: (a) Mesh of ejector, also showing the definition of the puzzle position ( $L$ ), and (b) local refined mesh around nozzle exit; in both cases the flow area appears dark (darker corresponds to finer meshing) and any solid parts/walls appear white.

\subsection{Model validation}

It is common that an enhancement of the secondary pressure will improve the entrainment ratio of the ejector. The specific relationship between the entrainment ratio and the secondary pressure is a key ejector characteristic, and a correct prediction of this characteristic is considered significant in giving confidence that a CFD simulation is a reliable predictor of the flow within an ejector. Such a validation exercise has been performed and the results are shown in Figure 9.

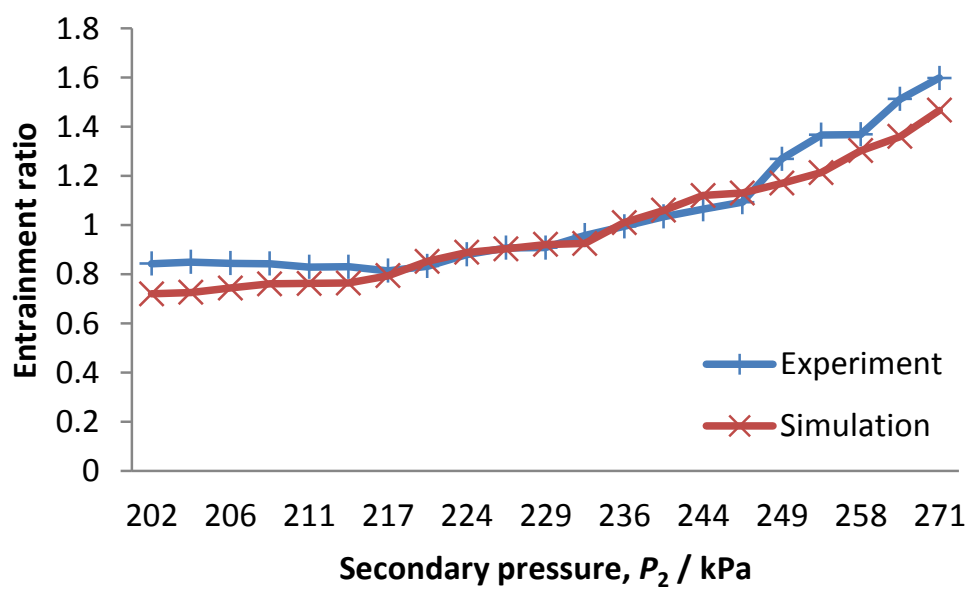

Figure 9: Comparison of the entrainment ratio from the experiments reported in Ref. [44] and the present simulations for the same nominal ejector design with $\mathrm{R} 600 \mathrm{a}$, a variable motive pressure from $P_{1}=613$ to $900 \mathrm{kPa}$ and corresponding discharge pressure from $P_{\mathrm{d}}=295$ to $308 \mathrm{kPa}$. 
In Figure 9 we compare directly results for the nominal ejector design considered in the CFD simulations in the present work to experimental data reported in the literature (taken directly from Ref. [44]) for the same ejector design under the same working conditions, with saturated R600a (i.e. pentane) employed as a dry refrigerant. For full details of the experiments the reader is referred to Ref. [44]. The thermodynamic properties of R600a were obtained from REFPROP.

It can be seen that this general relationship is reproduced well by the CFD simulations. A slightly larger deviation between the prediction of the entrainment ratio and the experimentally obtained data is observed when the secondary pressure is far away from the design point (recall from Section 3.2 that the design point has a motive pressure of $P_{1}=780 \mathrm{kPa}$, a secondary pressure of $P_{2}=229 \mathrm{kPa}$ and a discharge pressure of $P_{\mathrm{d}}=308 \mathrm{kPa}$ ), at the extreme ends of the plotted secondary pressure range (low and high). The largest deviation is $14.6 \%$ and $8.2 \%$, in correspondence with a secondary pressure of 202 and $271 \mathrm{kPa}$ respectively. A better agreement between experiment and simulation occurs around the design point ejector, with errors from $-5.3 \%$ to $3.4 \%$ over a secondary pressure range of $217-246 \mathrm{kPa}$. Consequently, the established model gives acceptable results of the ejector characteristics.

\section{Results and Discussion}

The EORC system being investigated in the present work can be used as a bottoming cycle to recover low- or medium-temperature waste-heat in conventional power plants or smaller CHP engines, or waste heat from a broad range of industrial processes. It can also utilize other renewable heat-sources, including solar energy or geothermal heat. It is generally considered that the EORC system is a promising technology for improved energy efficiency and sustainability; however, the losses caused by the process of irreversible mixing in the ejector (which are unavoidable owing the principle of operation of this component) can degrade the overall system performance [34-36]. This makes it reasonable and necessary to concentrate on reducing these irreversible mixing losses inside the ejectors, which is considered in this section.

\subsection{Operating temperatures/pressures}

In an EORC, the primary pressure in the ejector is derived from the outlet pressure at the exit of the turbine. An enhancement in the primary pressure is beneficial to ejector performance $[41,49]$ leading to an increased cooling capacity of the refrigeration system, however, the work output from the turbine expander is inevitably reduced. Consequently, the primary pressure of the ejector is a key design parameter, whose value should be selected in order to allow an acceptable compromise between power output and refrigeration capacity.

The temperatures of the generator, the evaporator and the condenser in a refrigeration cycle are considered important parameters to validate the system's performance, and correspond to the primary, secondary and discharge pressures of the ejector, respectively. Cooling from an EORC can be provided at the evaporator, as illustrated in Figure 4 ('cooling water'), so the pressure (and thus temperature) in the evaporator is critical to the refrigeration performance of the system, and is related to the secondary pressure in the ejector that is proposed to be saturated. When the primary pressure is fixed, an enhancement in the secondary pressure helps to increase the entrainment ratio and the cooling capacity of the ejector. 
In Figure 9 the entrainment ratio is seen to increase almost linearly from about 1.05 to 1.25 -1.30 with an increase in the secondary pressure from $P_{2}=190$ to $230 \mathrm{kPa}$, while keeping a fixed discharge pressure of $P_{\mathrm{d}}=250,300$ or $350 \mathrm{kPa}$, and a nozzle position of $L=6 \mathrm{~mm}$. This leads to two contradicting effects, from which a balance is sought. On the one hand, a higher entrainment ratio (cooling mass flow rate) is beneficial to ejector performance, increasing cooling capacity, while on the other, higher secondary pressures act to deteriorate cooling performance because higher pressures correspond to higher temperatures on the working-fluid side of the evaporator, which has the undesirable effect of increasing the cooling temperature and affecting the delivered COP of the refrigeration sub-system. It is also evident, and interesting, from Figure 9, that an increase in the discharge pressure leads to a slight deterioration in the entrainment ratio, with the ratio is rather insensitive to changes in this operational parameter $(<5 \%)$. The fluid at the outlet of the ejector discharges into the condenser, where a high condenser pressure makes it unsuitable for refrigerant liquefaction. In addition, the flow rate of the refrigerant reduces through the throttling device; thus leading to a decrease in the ejector's cooling capacity.

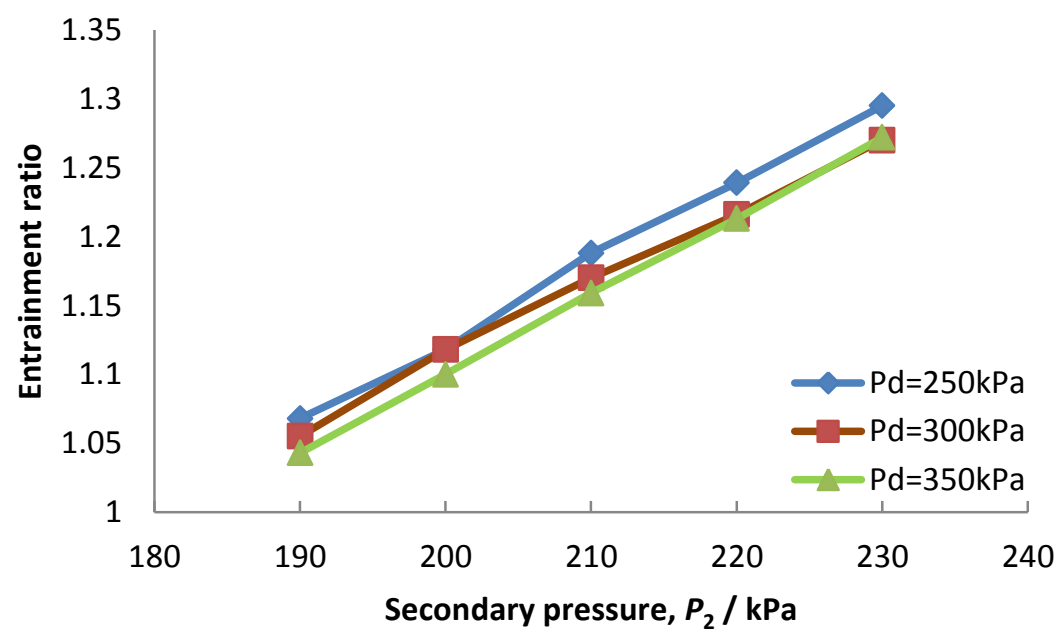

Figure 9: Effect of secondary pressure on entrainment ratio for different discharge pressures of $P_{\mathrm{d}}=250,300,350 \mathrm{kPa}$ separately with a nozzle position of $L=6 \mathrm{~mm}$

\subsection{Nozzle position}

The nozzle position, which is the distance $L$ between the nozzle exit and the mixing chamber entrance, as defined and indicated in Figure 8a, is believed to play an important role in determining ejector performance and controlling the entrainment ratio [48,50,51]. Figure 10 shows that the relationship between this distance and the resulting degree of entrainment is non-trivial and non-monotonic. Specifically, the highest entrainment ratios for this ejector design are attained when the nozzle position is at a nominal $L=6 \mathrm{~mm}$ from the chamber, which appears as the optimum position. When the distance is less than $6 \mathrm{~mm}$, the suction effect of primary fluid is weakened because some of accelerated primary fluid rushes into mixing chamber without expansion. As a result, the secondary fluid has a decreased motive to enter and mix with primary fluid, leading to a reduced entrainment ratio, which is the case when the nozzle position is at $L=$ 4 or $5 \mathrm{~mm}$ in Figure 10. On the contrary, when the nozzle distance $L$ is increased beyond $6 \mathrm{~mm}$, the primary fluid experiences over-expansion, leading to a considerable energy loss. This in turn results in a drop in the entrainment ratio. For this reason, it is important to pay particular 
attention when selecting the optimal nozzle position so as to achieve a high entrainment ratio, reduced energy losses and improved ejector performance. Figure 10 also shows that, having selected a nozzle position design, the entrainment ratio increases gradually with the secondary pressure, with the highest ratios observed when the suction pressure rises to $P_{2}=244-246 \mathrm{kPa}$.

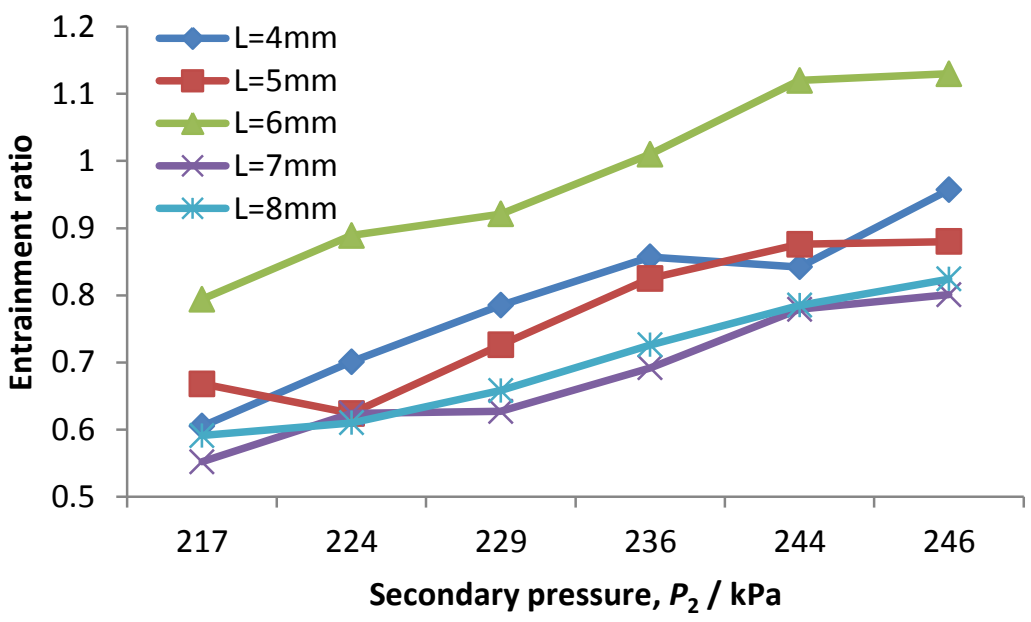

Figure 10: Effect of nozzle position on entrainment ratio with different nozzle positions with a discharge pressure $P_{\mathrm{d}}=308 \mathrm{kPa}$ and motive/secondary pressure combinations as per Table 2

\subsection{Ejector performance}

We now proceed to consider in detail (in Figures 11 - 14) the pressure distributions established inside the ejector for the different geometrical design (i.e. nozzle position $L$ ) variations and operating conditions (i.e. secondary pressure $P_{2}$ ) variations considered above. As expected, the static pressure of the primary fluid does not change considerably when the cross-sectional area of flow is constant. This can be seen, for example in Figure 11 (and also Figure 12) over an approximate axial position range (this position has its origin at the far left-hand entry point of the flow into the modelled domain; see Figures 7 and 8) from 28 to $43 \mathrm{~mm}$. On the other hand, significant pressure variations are induced by sudden changes in cross-sectional flow area and consequent changes in fluid velocity, as would be expected in accordance to Bernoulli's equation.

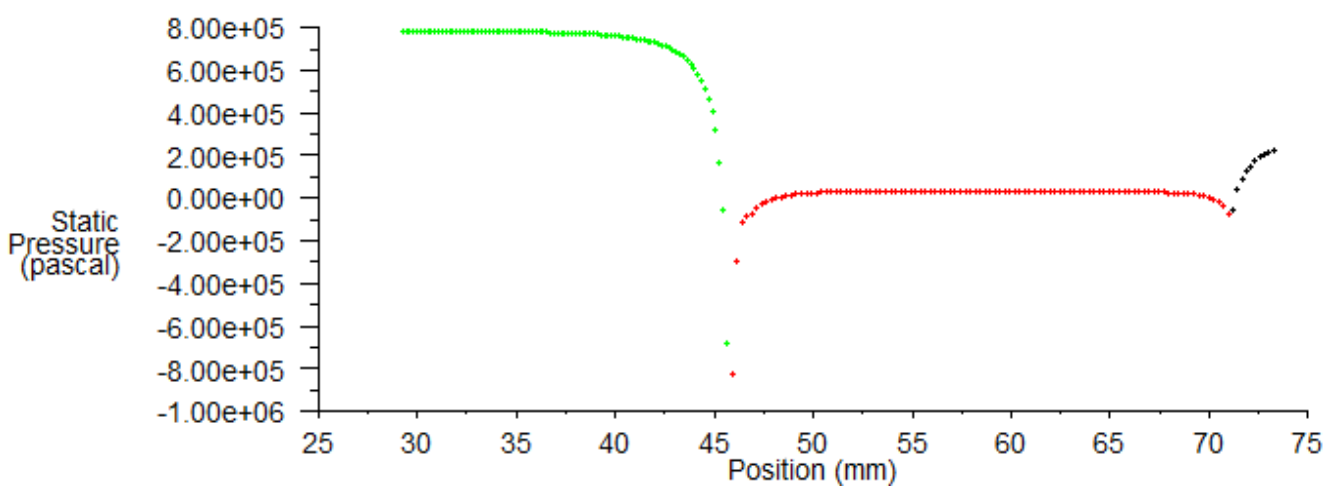

Figure 11: Static (gauge) pressure distribution on the nozzle wall for an ejector design with a nozzle position of $L=4 \mathrm{~mm}$, a discharge pressure of $P_{\mathrm{d}}=308 \mathrm{kPa}$, secondary pressure of $P_{2}=229 \mathrm{kPa}$ and motive pressure of $P_{1}=780 \mathrm{kPa}$ 


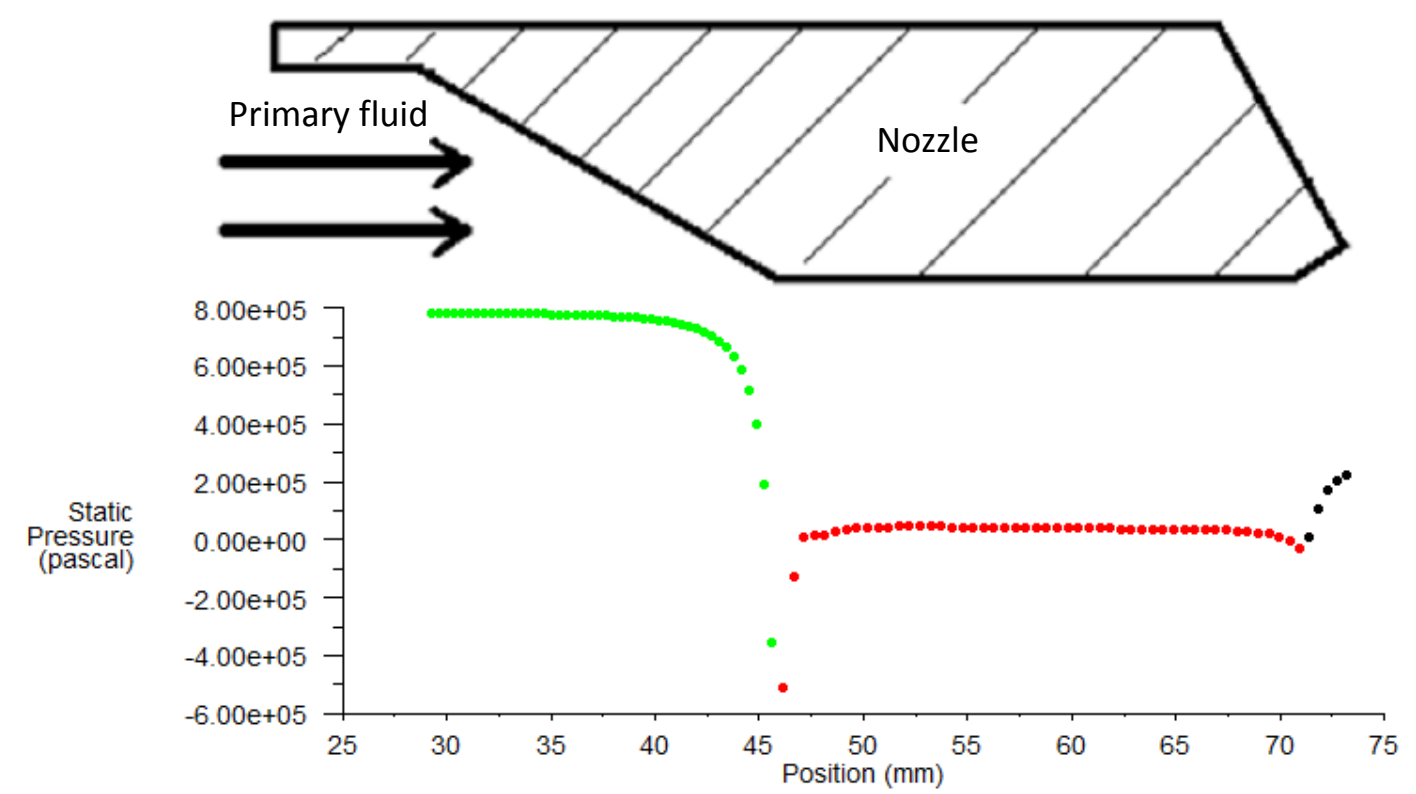

Figure 12: Static (gauge) pressure distribution on the nozzle wall for an ejector design with a nozzle position of $L=6 \mathrm{~mm}$, a discharge pressure of $P_{\mathrm{d}}=308 \mathrm{kPa}$, secondary pressure of $P_{2}=229 \mathrm{kPa}$ and motive pressure of $P_{1}=780 \mathrm{kPa}$

In Figures 11 and 12, it a large static-pressure drop is observed in the axial region from 43 to $47 \mathrm{~mm}$. In Figure 11 (with $L=4 \mathrm{~mm}$ ), the local static (gauge) pressure at an axial position of around $47 \mathrm{~mm}$ inside the nozzle decreases dramatically to almost $-9 \times 10^{5} \mathrm{~Pa}$, whereas the pressure at the same axial position in Figure 12 (with the optimal $L=6 \mathrm{~mm}$ ) is about $-5.5 \times 10^{5} \mathrm{~Pa}$. Therefore, the nozzle position can introduce considerable differences to the static pressure distribution within the ejector nozzle for the same otherwise operating conditions, and especially at the stated region where the flow first reaches the minimum cross-sectional area, as shown.

Similarly, a significant pressure change is observed at the divergence at the nozzle exit, where the kinetic energy (dynamic pressure) of the primary fluid is transformed into pressure energy. It is unavoidable to have a certain degree of energy loss at the nozzle, although some effort can be placed in keeping this loss low, for example by smoothing the edges of the nozzle as shown in Figures $8 \mathrm{~b}$ and 12. It should be noted that although beneficial to performance, such a design modification will be associated with an increased complexity in manufacturing and give rise to an increased cost of production, making ejectors less suitable for practical deployment.

Static pressure alone is not sufficient to allow for a rigorous discussion of the energy (or, by extension, exergy) losses in the ejector nozzle. In general, such losses in a mixing process can arise from thermal mixing (drop in temperature) and fluid-mechanical mixing (drop in pressure), however, given the supersonic flows in our case, the losses are dominated by the latter due to the very high kinetic energy (compared to the enthalpy) of the flows involved, such that they can be considered to manifest largely as total pressure drops. Consequently, total pressure losses through the ejector nozzle (i.e. between the nozzle inlet and exit) for different nozzle positions or conditions can be considered as a measure of exergy losses. Relevant results are shown for the same otherwise working conditions (stated in the captions) in Figures 13 and 14 for both static and total pressures, respectively. The static and total pressure losses are inversely related to the secondary pressure of the ejector under the same operating conditions, such that as the 
secondary pressure rises, the pressure loss reduces. The reduction appears to be close to linear. This result can be understood by considering that the flow in the ejector, and therefore also its overall performance, benefits from an enhancement in the secondary pressure; see also Ref. [40].

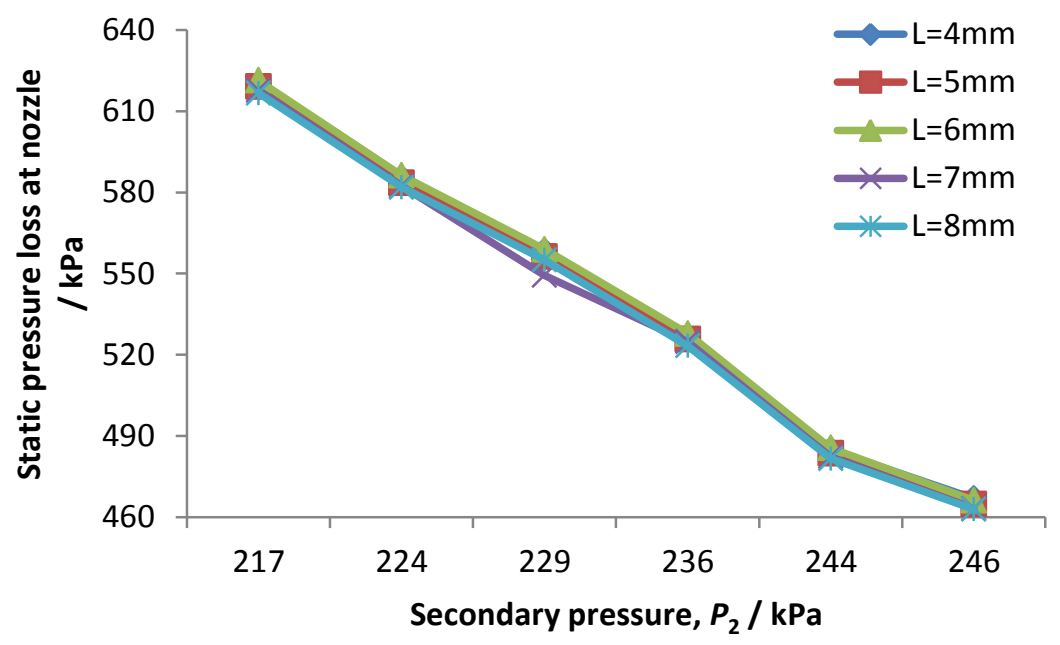

Figure 13: Static pressure loss through the ejector nozzle (i.e. between the ejector nozzle inlet and exit); the full set of working conditions for which data is presented in this plot (including discharge pressures) are given in Table 2

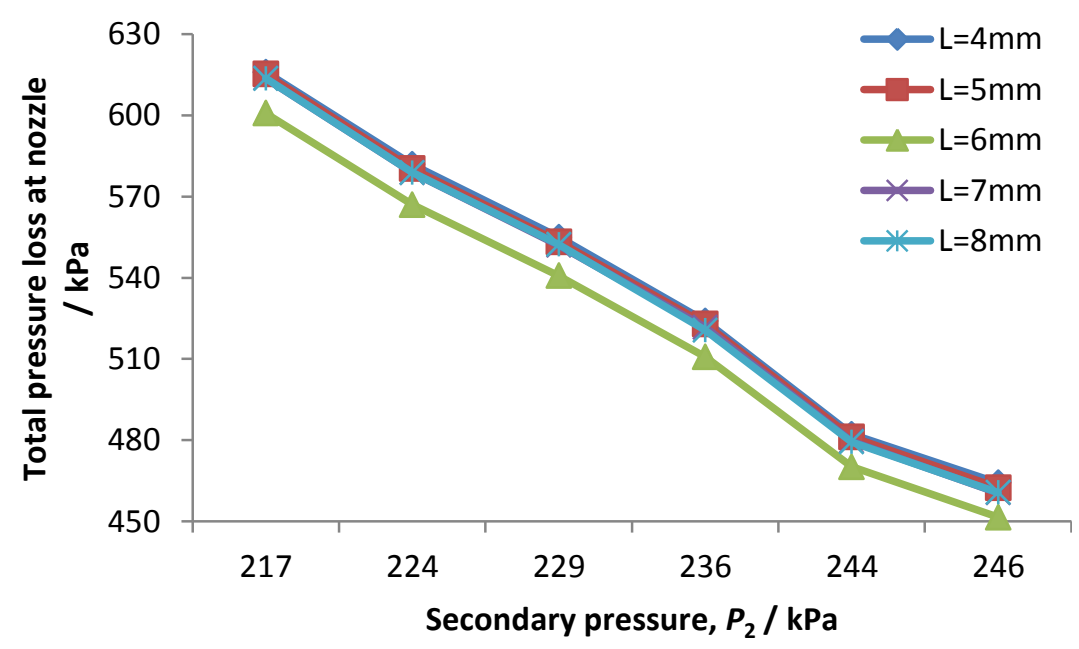

Figure 14: Total pressure loss between the ejector nozzle inlet and exit for designs with different nozzle positions $(L)$; the remaining working conditions are given in Table 2

Furthermore, there is less than a $1 \%$ variation in the static pressure loss when the nozzle position $L$ is varied from $4 \mathrm{~mm}$ to $8 \mathrm{~mm}$, as shown in Figure 13. On the other hand, a noteworthy improvement is achieved in the total pressure loss plotted in Figure 14, as the nozzle position $L$ is varied under the same operating conditions. It can be seen from this figure that the total energy loss for the ejector design with the optimal nozzle position $(L=6 \mathrm{~mm}$ ) clearly departs from the other designs (the difference is more than $2 \%$ ); the reduced total pressure loss corresponds to a reduced energy (and exergy) loss, a higher entrainment ratio and improved ejector performance, in agreement with the findings in Section 4.2. 
Table 2: Conditions used in the simulations shown in Figures 10, 13 and 14; note that each given value of the secondary pressure corresponds to the equivalent value of the discharge pressure directly below it, which was fixed for all simulations with the same secondary pressure

\begin{tabular}{|c|c|}
\hline Parameter & Value / kPa \\
\hline Motive pressure, $P_{1}$ & $705,722,756,780,802,830$ \\
\hline Secondary pressure, $P_{2}$ & $217,224,229,236,244,246$ \\
\hline Discharge pressure, $P_{\mathrm{d}}$ & $308,307,308,307,308,307$ \\
\hline
\end{tabular}

\section{Conclusions}

ORC systems incorporating ejectors (EORCs) are capable of providing both power and a cooling capacity, and potentially a heating output from the rejected heat, and are being considered by a number of investigators. Inherent losses caused by the mixing process between the primary/ motive and secondary/suction streams inside the ejector of such a system degrade the thermodynamic performance of this component and, by extension, of the overall EORC system. There is, therefore, an incentive to minimize these mixing losses and improve performance.

This work considers the detailed flow and transport processes in an ejector with CFD in order to understand the underlying reasons for these losses as evidenced through important parameters such as the entrainment ratio, and going beyond this understanding, to quantify the magnitude of these losses. This the present case, the thermodynamic (irreversibility) losses can be considered to manifest largely as total pressure drops due to the very high flow kinetic energy (given the supersonic flows) involved, compared to the flow enthalpy. Variations to the geometric design of the ejector nozzle, as well as operation at different conditions across the component were considered; the latter in an attempt to understand part-load performance.

The main conclusions that can be drawn from the present work suggest that improved EORC designs can be proposed based on the following observations:

1) The refrigeration performance of an EORC system, including the achieved entrainment ratio and cooling capacity (and thus COP), is affected significantly by the evaporator conditions (temperature, pressure, flow rate), since the secondary fluid stream is supplied from the evaporator. A high temperature/pressure or low flow rate in this stream will worsen the cooling performance of the refrigeration part of the system, and can increase energy costs.

2) An increase in the discharge pressure is also undesirable when considering the entrainment ratio, but this effect was rather limited in the investigated range of parameters $(<5 \%)$.

3) The primary nozzle position within an ejector is another important design parameter, which is known to affect the ejector's performance (including the entrainment and pressure-lift ratios) [52]. A low entrainment ratio is known to lead to a decreased cooling capacity that is detrimental to evaporator performance, as well as ejector pressure recovery. So, an optimum distance exists between the nozzle exit and the mixing section inlet that ensures a maximum entrainment ratio, the best efficiency and lowest loss in the ejector. A value of $6 \mathrm{~mm}$ was found in the geometry examined in the present work. It is suggested that a movable nozzle providing a flexible nozzle position could better satisfy off-design operating conditions.

4) It is expected that a reduction in the irreversibilities within the system will lead to an overall enhancement in the system's performance. It has been shown that the performance of the ejector depends strongly on the geometry and position of the primary nozzle, and that losses 
arise from frictional effects and flow separation. These effects can be addressed at the design stages, by careful streamlining of the ejector to improve nozzle efficiency $[53,54]$. Once the diameters of the nozzle have been set, the edges of the nozzle can be designed (smoothed) to reduce the energy loss when primary fluid flows through the ejector, while paying attention to any increased manufacturing or production costs associated with this design. Experimental data are necessary to understand how the ejector nozzle performance can be improved and how this can affect the efficiency of the system.

5) Both the static and total pressure losses are inversely related (almost linearly so) to the secondary pressure in the ejector, while keeping other working parameters and operating conditions unchanged. This suggests that the ejector is sensitive to the secondary pressure and that an enhancement of the secondary pressure will act to decrease energy (and exergy) losses. The static pressure drop along the nozzle axis is also affected by the nozzle position. Variations to the nozzle position affect the total pressure loss (even more than the static pressure loss). A reduced total pressure loss leads to a lower energy and exergy loss, a higher entrainment ratio and better overall ejector performance. The optimal nozzle position thus identified, by considering the entrainment, is also the best design in this regard.

\section{Acknowledgement}

This research was supported by National Natural Science Foundation of China (No. 51306027).

\section{References}

[1] Markides CN. The role of pumped and waste heat technologies in a high-efficiency sustainable energy future for the UK. Appl Therm Eng 2013; 53(2): 197-209.

[2] Markides CN. Low-concentration solar-power systems based on organic Rankine cycles for distributed-scale applications: Overview and further developments. Front Energy Res 2015, 3(47). [3] Freeman J, Hellgardt K, Markides CN. An assessment of solar-powered organic Rankine cycle systems for combined heating and power in UK domestic applications. Appl Energy 2015; 138: 605-620. [4] Freeman J, Hellgardt K, Markides CN. Working fluid selection and electrical performance optimisation of a domestic solar-ORC combined heat and power system for year-round operation in the UK. Appl Energy 2016; doi:10.1016/j.apenergy.2016.04.041.

[5] Oyewunmi OA, Taleb Al, Haslam AJ, Markides CN. An assessment of working-fluid mixtures using SAFT-VR Mie for use in organic Rankine cycle systems for waste-heat recovery. Comput Therm Sci 2014; 6(4): 301-316.

[6] Oyewunmi OA, Taleb AI, Haslam AJ, Markides CN. On the use of SAFT-VR Mie for assessing large-glide fluorocarbon working-fluid mixtures in organic Rankine cycles. Appl Energy 2016; 163: 263-282.

[7] Safarian S, Aramoun F. Energy and exergy assessments of modified organic Rankine cycles. Energy Reports 2015; 1: 1-7.

[8] Bombarda P, Invernizzi CM, Pietra C. Heat recovery from diesel engines: A thermodynamic comparison between Kalina and ORC cycles. Appl Therm Eng 2010; 30: 212-219.

[9] Escalona JM, Sánchez D, Chacartegui R, Sánchez T. Part-load analysis of gas turbine \& ORC combined cycles. Appl Therm Eng 2012; 36: 63-72.

[10] Desai, N.B., Bandyopadhyay, S. Process integration of organic Rankine cycle. Energy 2009; 34 : 1674-1686.

[11] Dai Y, Wang J, Gao L. Parametric optimization and comparative study of organic Rankine cycle 
(ORC) for low grade waste heat recovery. Energy Convers Manag 2009; 50: 576-582.

[12] Demirkaya G, Vasquez Padilla R, Goswami DY, Stefanakos E, Rahman MM. Analysis of a combined power and cooling cycle for low-grade heat sources. Int J Energy Res 2011; 35: 1145-1157.

[13] Habibzadeh A, Rashidi MM, Galanis N. Analysis of a combined power and ejector-refrigeration cycle using low temperature heat. Energy Convers Manag 2013; 65: 381-391.

[14] Yang XY, Zhao L, Li HL, Yu ZX. Theoretical analysis of a combined power and ejector refrigeration cycle using zeotropic mixture. Appl Energy 2015; in press.

[15] Boyaghchi FA, Heidarnejad P. Thermoeconomic assessment and multi objective optimization of a solar micro CCHP based on organic Rankine cycle for domestic application. Energy Convers Manag 2015; 97: 224-234.

[16] Goswami DY. Solar thermal power: Status of technologies and opportunities for research. Heat Mass Transf 1995; 95: 57-60.

[17] Goswami DY, Xu F. Analysis of a new thermodynamic cycle for combined power and cooling using low and mid temperature solar collectors. J Sol Energy Eng 1999; 121 (2): 91-97.

[18] Martin C, Goswami DY. Effectiveness of cooling production with a combined power and cooling thermodynamic cycle. Appl Therm Eng 2006; 26: 576-582.

[19] Tamm G, Goswami DY, Lu S, Hasan AA. Theoretical and experimental investigation of an ammonia-water power and refrigeration thermodynamic cycle. Sol Energy 2004; 76 (2): 217-228.

[20] Gosney WB. Principle of refrigeration. Cambridge University Press, Cambridge. 1982.

[21] Abdulateef JM, Sopian K, Alghoul MA, Sulaiman MY. Review on solar-driven ejector refrigeration technologies. Renew Sust Energy Rev 2009; 13(6-7): 1338-1349.

[22] Keenan JH, Newman EP. A simple air ejector. Trans ASME J Appl Mech 1946; 64: A75-81.

[23] Keenan JH, Newman EP, Lustwerk F. An investigation of ejector design by analysis and experiment. J Appl Mech 1950; 17: 299-309.

[24] Riffat SB, Gan G, Smith S. Computational fluid dynamics applied to ejector heat pumps. Appl Therm Eng 1996; 16(4): 291-297.

[25] Rogdakis ED, Alexis GK. Investigation of ejector design at optimum operating condition. Energy Convers Manag 2000; 41: 1841-1849.

[26] Sankarlal T, Mani A. Experimental investigations on ejector refrigeration system with ammonia. Renew Energy 2007; 32: 1403-1413.

[27] Zhang K, Shen SQ, Yang Y, Tian XW. Experimental investigation on adjustable ejector performance. J Energy Eng 2012; 138(3): 125-129.

[28] Rashidi MM, Bég OA, Habibzadeh A. First and second law analysis of an ejector expansion Joule-Thomson cryogenic refrigeration cycle. Int J Energy Res 2012; 36: 231-240.

[29] Dahmani A, Galanis N, Aidoun Z. Optimum design of ejector refrigeration systems with environmentally benign fluids. Int J Therm Sci 2011; 50: 1562-1572.

[30] Mazzelli F, Milazzo A. Performance analysis of a supersonic ejector cycle working with R245fa. Int J Refrig 2015; 49: 79-92.

[31] Oliveira AC, Afonso C, Matos J, Riffat S, Nguyen M, Doherty P. A combined heat and power system for buildings driven by solar energy and gas. Appl Therm Eng 2002; 22(6): 587-593.

[32] Li XG, Li XJ, Zhang QL. The first and second law analysis on an organic Rankine cycle with ejector. Sol Energy 2013; 93: 100-108.

[33] Yari M, Mehr AS, Mahmoudi SMS. Thermodynamics analysis and optimization of a novel dual-evaporator system powered by electrical and solar energy sources. Energy 2013; 61: 646-656. 
[34] Dai Y, Wang J, Gao L. Exergy analysis, parametric analysis and optimization for a novel combined power and ejector refrigeration cycle. Appl Therm Eng 2009; 29: 1983-1990.

[35] Zheng B, Weng YW. A combined power and ejector refrigeration cycle for low temperature heat sources. Sol Energy 2010; 84: 784-791.

[36] Wang J, Dai Y, Sun Z. A theoretical study on a novel combined power and ejector refrigeration cycle. Int J Refrig 2009; 32: 1186-1194.

[37] Huang BJ, Chang JM, Wang CP, Petrenko VA. A 1-D analysis of ejector performance. Int J Refrig 1999; 22: 354-364.

[38] Alexis GK. Estimation of ejector's main cross sections in steam-ejector refrigeration system. Appl Therm Eng 2004; 24: 2657-2663.

[39] Zhu YH, Cai WJ, Wen CY, Li YZ. Shock circle model for ejector performance evaluation. Energy Convers Manag 2007; 48: 2533-2541.

[40] Bartosiewicz Y, Aidoun Zine, Desevaux P, Mercadier Yves. Numerical and experimental investigations on supersonic ejectors. Int J Heat Fluid Flow 2005; 26(1): 56-70.

[41] Chunnanond K, Aphornratana S. Ejectors: Application in refrigeration technology. Renew Sust Energy Rev 2004; 8: 129-155.

[42] Huang BJ, Jiang CB, Hu FL. Ejector performance characteristics and design analysis of jet refrigeration system. Trans ASME 1985; 107: 792-802.

[43] Wu S, Eames IW. A novel absorption-recompression refrigeration cycle. Appl Therm Eng 1998; 19: $1149-1157$.

[44] Zheng B. Theoretical and experimental study on a combined power and ejector refrigeration cycle for low temperature heat sources. Doctoral Dissertation, Shanghai Jiaotong University 2011.

[45] Pianthong K, Sheehanam W, Behnia M, Sriveerakul T, Aphornratana S. Investigation and improvement of ejector refrigeration system using computational fluid dynamics technique. Energy Convers Manag 2007; 48: 2556-2564.

[46] Zhang K, Shen SQ, Yang Y. Numerical investigation on performance of the adjustable ejector. Int J Low-Carbon Technol 2010; 5(2): 51-56.

[47] Yinhai Zhu, Wenjian Cai, Changyun Wen, Yanzhong Li. Numerical investigation of geometry parameters for design of high performance ejectors. Appl Therm Eng 2009; 29: 98-905.

[48] Natthawut Ruangtrakoon, Tongchana Thongtip, Satha Aphornratana, Thanarath Sriveerakul. CFD simulation on the effect of primary nozzle geometries for a steam ejector in refrigeration cycle. Int J Therm Sci 2013; 63: 133-145.

[49] Chua KJ, Chou SK, Yang WM. Advances in heat pump systems: A review. Appl Energy 2010; 87: 3611-3624.

[50] Jianyong Chen, Sad Jarall, Hans Havtun, Björn Palm. A review on versatile ejector applications in refrigeration systems. Renew Sust Energy Rev 2015; 49: 67-90.

[51] Szabolcs Varga, Armando C. Oliveira, Bogdan Diaconu. Influence of geometrical factors on steam ejector performance - A numerical assessment. Int J of Refrig 2009; 32: 1694-1701.

[52] Chen X, Omer S, Worall M, Riffat S. Recent developments in ejector refrigeration technologies. Renew Sustain Energy Rev 2013; 19: 629-651.

[53] Sharifi N, Sharifi M. Reducing energy consumption of a steam ejector through experimental optimization of the nozzle geometry. Energy 2014; 66: 860-867.

[54] Sun DW, Eames IW. Performance characteristics of HCFC-123 ejector refrigeration cycles. Int J Energy Res 1996; 20: 871-885. 